УДК 616.716.4-001.5-08-053.88

DOI 10.31612/2616-4868.1-4.2018.10

Н.С. Мирзаева

\title{
НЕКОТОРЫЕ АСПЕКТЫ ПАТОГЕНЕЗА ЧЕРЕПНО-МОЗГОВОЙ ТРАВМЫ (ОБЗОР ЛИТЕРАТУРЫ)
}

Ургенчский филиал Ташкентской медицинской академией, г. Ургенч, Республика Узбекистан

\section{Резюме}

Представлен обзор литературы, определены особенности легкой черепно-мозговой травмы. Описаны ряд синдромов, возникающих при легкой черепно-мозговой травме, факторы риска и субъективные клинические проявления легких черепно-мозговых травм. Нарушения, возникающие после перенесенных черепно-мозговых травм, приобретают затяжное, проградиентное течение с длительной утратой трудоспособности среди лиц наиболее молодого трудоспособного возраста. Современная неврология столкнулась с тенденцией роста частоты черепно-мозговых травм с 25\% до 80\% от общего количества неврологических болезней. Это связано с современными процессами урбанизации, внеАрением современных технологий, дорожно-транспортными происшествиями (АТП), локальными вооруженными конфликтами и пр. факторами. В основном травматизму подвержены лица мужского пола в возрасте 20-50 лет, что определяет его социальное значение. Исходы острой черепно-мозговой травмы могут быть различными: от полного выздоровления до развития у 30-96\% пострадавших различных неблагоприятных последствий и осложнений. К последствиям ЧМТ относится неврологическая патология, выявляемая спустя 3-12 месяцев и более после травмы, и клинические проявления могут сохраняться и видоизменяться в виде отдельных остаточных явлений.

Ключевые слова: черепно-мозговая травма, сотрясение головного мозга, посттравматическая амнезия.

\section{ВВЕДЕНИЕ}

Черепно-мозговая травма (ЧМТ) относится к наиболее распространённым видам повреждений (до $50 \%$ всех видов травм) и в последние десятилетия характеризуется тенденцией роста удельного веса травм мозга. Ежегодно в мире от ЧМТ погибают 1,5 млн человек, а 2,4 млн становятся инвалидами [3, 4, 11]. Современная неврология столкнулась с тенденцией роста частоты черепномозговых травм с $25 \%$ до $80 \%$ от общего количества неврологических болезней. Это связано с современными процессами урбанизации, внедрением современных технологий, дорожно-транспортными происшествиями (ДТП), локальными вооруженными конфликтами и пр. факторами. В основном травматизму подвержены лица мужского пола в возрасте 20-50 лет $(71,7 \%)$, что определяет его социальное значение. Большую часть составляют ДТП $(42,1 \%)$ и производственные травмы (38\%) [1-2]. По данным ВО3, ежегодный прирост частоты черепно-мозговых повреждений увеличивается в среднем на $2 \%$ в год [4].

Таким образом, ЧМТ всё больше становится мультидисциплинарной проблемой, актуальность которой возрастает для нейрохирургов, неврологов, психиатров, травматологов, рентгенологов и др. По данным Национального института общественного здоровья, ежегодный ущерб от ЧМТ оценивается в 500 млрд. руб. [4, 6, 12].

В то же время, последние наблюдения показывают недостаточное качество, несоблюдение преемственности консервативной терапии. Нарушения, возникающие после перенесенных ЧМТ, приобретают затяжное, проградиентное течение с длительной утратой трудоспособности среди лиц наиболее молодого трудоспособного возраста. 
По классификации (ЧМТ) разделяют на легкую, среднетяжелую и тяжелую. К легкой ЧМТ относят сотрясение головного мозга и ушиб головного мозга легкой тяжести [1]. Если в понимании тяжелой ЧМТ отечественные и зарубежные авторы в целом сходятся, то в отношении легкой ЧМТ существуют различия. Американские авторы группируют травму головы на тяжелую (severe), средней тяжести (moderate) и умеренную (mild). Некоторые американские авторы умеренную травму головы, в свою очередь, делят на легкую (minor) и минимальную (minimal) [11-13]. Минимальная травма головы соответствует сотрясению головного мозга отечественной классификации, а легкая травма головы - повреждению мозга, напоминающему ушиб легкой степени по отечественной классификации. В дальнейшем мы будем употреблять термин "легкая травма головного мозга" (ЛТГМ), поскольку термин "легкая ЧМТ" в данной ситуации нецелесообразен, так как наибольшее значение имеют размер и степень поражения мозга, в то время как травма черепа играет лишь косвенную роль.

Частота госпитализации по поводу ЛТГМ в США - 131 случай на 100000 населения и составляет от $60 \%$ до $82 \%$ всех госпитализаций из-за травмы головы. Учитывая такое огромное количество пациентов, ЛТГМ называют "скрытой эпидемией". На лечение таких пациентов в США тратится более 3,9 млрд. долларов в год $[4,5]$. Не располагая аналогичной отечественной статистикой, мы можем только догадываться об огромном экономическом ущербе, наносимом ЛТГМ.

ЛТГМ включает в себя две формы ЧМТ:

1. Сотрясение головного мозга - СГМ (commotio cerebri, brain concussion) - клинический синдром, обусловленный действием на головной мозг механических сил и характеризующийся потерей сознания на короткое время после травмы, без ближайших и отдаленных доказательств структурного повреждения мозга. Характерно отсутствие каких-либо остаточных явлений, кроме преходящей посттравматической амнезии и других неспецифических симптомов, таких как головокружение, головная боль и др. Диагноз СГМ может быть поставлен только ретроспективно. СГМ может возникнуть как при травме ускорениязамедления (импульсивной), так и при ударах по голове [1, 3, 4, 6].

Травма, вызывающая ротацию головы, чаще приводит к СГМ.

Механизм сотрясения мозга точно не известен. Предполагают, что происходит функциональное разобщение между стволом и полушариями мозга.
При этом не обнаруживаются макроскопические и гистологические изменения ткани мозга [2]. Определение "потеря сознания на короткое время" может интерпретироваться по-разному. В отечественной классификации временной интервал, отведенный для потери сознания при СГМ, колеблется от нескольких секунд до нескольких десятков минут, а для ушиба мозга легкой степени тяжести - от десятков минут до часа. На практике все это достаточно условно. Многие западные специалисты считают максимальным сроком продолжительность комы при СГМ 6 ч. [5]. Если пациент приходит в сознание до этого времени, то травма интерпретируется как сотрясение мозга с достаточно хорошим долгосрочным прогнозом. Если кома длится более 6 ч., повреждение ткани мозга практически несомненно. Сейчас все исследователи убеждены, что речь в этом случае идет о диффузном повреждении мозга, вызванном травмой ускорениязамедления, в результате которой аксоны в белом веществе полушарий и ствола растягиваются и/или срезаются.

Это отражено в классификации СГМ по степеням тяжести. В отечественной литературе 60-х и 70-х годов можно встретить деление СГМ на три степени тяжести: легкую, среднетяжелую и тяжелую. На уровне современных знаний СГМ тяжелой степени трактуется как ДАП, а оставшиеся две степени относятся к различным проявлениям СГМ в сегодняшнем его понимании. В западной литературе некоторые авторы выделяли 3 или 4 степени тяжести СГМ. В настоящее время деление СГМ на степени представляет лишь исторический интерес, хотя очень многое в патогенезе СГМ до настоящего времени непонятно. Вторым проявлением ЛТГМ является ушиб головного мозга легкой степени (УГМЛС), при котором микроскопически определяется негрубое повреждение вещества мозга в виде участков локального отека, точечных корковых кровоизлияний, возможно, в сочетании с ограниченным субарахноидальным кровоизлиянием в результате разрыва пиальных сосудов [1]. Разграничить СГМ и УГМЛС по продолжительности комы и посттравматической амнезии, а также по клиническим проявлением практически невозможно.

Основу патологоанатомической картины изолированных повреждений головного мозга составляют первичные травматические дистрофии и некрозы, расстройства кровообращения и организация тканевого дефекта. Сотрясения головного мозга характеризуются комплексом взаимосвязанных деструктивных, реактивных и компенсаторно-приспособительных процессов, протекающих на ультраструктурном уровне в синаптическом 
аппарате, нейронах, клетках. Ушиб мозга - повреждение, характеризующееся наличием в веществе мозга и в его оболочках макроскопически видимых очагов деструкции и кровоизлияний, в части случаев сопровождающихся повреждением костей свода, основания черепа. Непосредственное повреждение при ЧМТ гипоталамо-гипофизарных, стволовых структур и их нейромедиаторных систем обусловливает своеобразие стрессорного ответа. Нарушение метаболизма нейромедиаторов - важнейшая особенность патогенеза ЧМТ. Высокочувствительным к механическим воздействиям является мозговое кровообращение.

Основные изменения, развивающиеся при этом в сосудистой системе, выражаются спазмом или расширением сосудов, а также повышением проницаемости сосудистой стенки. Непосредственно с сосудистым фактором связан и другой патогенетический механизм формирования последствий ЧМТ - нарушение ликвородинамики. Изменение продукции ликвора и его резорбции в результате ЧМТ связано с повреждением эндотелия хориоидных сплетений желудочков, вторичными нарушениями микроциркуляторного русла мозга, фиброзом мозговых оболочек, в отдельных случаях ликвореей. Эти нарушения приводят к развитию ликворной гипертензии, реже - гипотензии.

Особенности легкой черепно-мозговой травмы заключаются в следующем: обратимость неврологических нарушений; процесс восстановления может затянуться на несколько недель и месяцев; при ДТП может быть хлыстовая травма шейного отдела позвоночника. До сих пор существуют различные мнения по поводу клинических проявлений ЛЧМТ, осложнений, прогноза и эффективных методов лечения, хотя имеется корреляция между симптомами и показателями ЭЭГ [1-3]. Очень часто после перенесенной легкой черепно-мозговой травмы (ЛЧМТ) у ряда пострадавших нарушаются нейрогуморальные, гемодинамические, ликвороциркуляторные показатели, что приводит к развитию микроструктурных изменений мозга с формированием травматической болезни головного мозга. Дальнейшее течение отдаленного периода ЛЧМТ зависит от индивидуальных особенностей организма, провоцирующих факторов, сопутствующих болезней, повторных травм и пр. Механизмы компенсации зависят от пластичности нервной системы, функциональных резервов и качества первичного лечения $[1,2]$. По данным российских нейрохирургов, у пациентов получивших ЛЧМТ, первичная декомпенсация посттравматического процесса наступала в среднем в 19, \% случаев, повторная - в $70,9 \%$, что свидетельствует о проградиентно- ремитирующем типе течения ЛЧМТ. При осмотре таких больных, в особенности с повторными ЧМТ, мы выявляли следующие синдромы, которые часто сочетались: церебральный $(53,6 \%)$; очаговый $(45,1 \%)$; гипоталамо-стволовой $(41,8 \%)$; гипертензионный $(39,2 \%)$; гидроцефальный $(18,9 \%)$; судорожный $(9,8 \%)$; астено-невротический $(58,8 \%)$.

1. Церебральная симптоматика включала в себя общемозговые проявления в виде головной боли, головокружения, тошноты, рвоты, дезориентировки со спутанностью сознания, слабости, боли при движении глазных яблок.

2. Очаговая симптоматика проявлялась в виде легкой асимметрии сухожильных рефлексов, ретроградной амнезии, нистагма, легкого гемипареза, патологических рефлексов.

3. Гипоталамо-стволовые признаки проявлялись в виде умеренных нарушений: роговичные рефлексы снижены с 1 или 2 сторон, легкая анизокория, клонический спонтанный нистагм. Или в виде выраженных нарушений: одностороннее расширение зрачков, клоно-тонический нистагм, снижение реакции зрачков на свет, умеренно выраженный парез взгляда вверх, двухсторонние патологические рефлексы, диссоциация менингеальных симптомов, мышечного тонуса и рефлексов по оси тела. Изредка встречались резко выраженные нарушения: грубая анизокория, грубый парез взгляда вверх, тонический множественный спонтанный нистагм или плавающий взгляд, грубая дивергенция глазных яблок по горизонтальной и вертикальной оси, грубо выраженные патологические рефлексы, грубая диссоциация менингеальных симптомов, мышечного тонуса и рефлексов по оси тела.

4. Гипертензионный синдром проявлялся в виде преходящего менингеального синдрома, бради- и тахикардии, урежения дыхания (триада Кушинга), транзиторного увеличения уровня артериального давления на 10-15 мм рт. ст., головных болей, головокружения, тошноты, рвоты, болей в области глазных яблок, чувства выдавливания глазных яблок, общего беспокойства, нарушения сна, повышенной сексуальной активности, перепадов настроения, раздражительности. Больные были капризными, гиперактивными, но быстро истощались. Могли быть икота, сонливость, нарушение зрения.

5. Гидроцефальный синдром во многом имел схожие клинические признаки с гипертензионным синдромом, но в тоже время встречался изолированно в виде ограниченной водянки головного 
мозга. Ряд авторов выделяют его в отдельный синдром, но другие исследователи считают, что он един в рамках гипертензионно-гидроцефального синдрома [3-6].

6. Судорожный синдром проявлялся у больных в виде непроизвольных мышечных сокрашений вследствие раздражения нейронов различных структур головного мозга (двигательных ядер ствола, базальных ганглиев, передних рогов спинного мозга, периферических нервов), отвечающих за двигательный контроль. По механизму развития они подразделяются на эпилептические (вызванные патологическим синхронным разрядом большой группы нейронов коры головного мозга) и неэпилептические в виде быстрых клонических и более медленных стойких тонических, а также смешанные. Судорожные припадки носили различный характер: от парциальных припадков типа судорожного подергивания в конечностях на фоне сохраненного сознания до судорог по типу «Джексоновский марш». При очаговом поражении височных и лобных долей встречались сложные парциальные приступы с координированными движениями и автоматизмами (потирание рук, облизывание губ и пр.) на фоне помраченного сознания. При кратковременной утрате сознания (обмороках) возникали клонические судороги с триадой Кушинга. Стволовые судороги имели приступообразный тонический характер по типу гормеотонии (повторяющиеся тонические спазмы в конечностях).

Встречались также мультифокальная миоклония в виде отрывистых, неритмичных, разбросанных гиперкинезов, с вовлечением различных мышечных групп. Чаще всего характер судорог имел четкую корреляцию с областью поражения головного мозга при черепно-мозговой травме и тяжестью травмы.

7. Астено-невротический синдром проявлялся: a) психофизическим нарушениями - повышенной утомляемостью, снижением толерантности к психофизическим нагрузкам, быстрой истощаемостью, вялостью, неустойчивостью фона настроения, раздражительностью, вспыльчивостью, нарушением сна;

б) интеллектуально-мнестическими нарушениями в виде снижения концентрации, уровня и объема внимания, затруднения запоминания, уменьшения скорости мыслительных процессов, торможения;

в) психоэмоциональными нарушениями «умственная жвачка», снижение уверенности, самооценки, мотиваций, уменьшение запросов, падения социальной активности; г) сексуальными нарушениями - ослаблением эрекции, преждевременной эякуляциэй, фригидностью, импотенцией и пр. [1, 2, 4-7].

При ЧМТ в патогенезе морфологических нарушений значительную роль наряду с непосредственным повреждением нервных элементов играют гипоксические и дисметаболические нарушения. ЧМТ, особенно тяжёлая, вызывает расстройства дыхания и кровообращения, что усугубляет имеющиеся дисциркуляторные церебральные нарушения и в совокупности приводит к более выраженной гипоксии мозга. Выделяют три базисных периода в течении травматической болезни головного мозга: острый, промежуточный, отдалённый. После пробуждения пациента возможны более или менее адекватные реакции. После восстановления сознания, но не более чем через 24 ч., может сохраняться некоторая спутанность сознания. У всех больных отмечается хотя бы незначительная амнезия, как правило ретро и/или антероградная. Могут быть содружественные или несодружественные плавающие движения глазных яблок, при этом глазодвигательные рефлексы сохраняются. Сохраняется реакция зрачков на свет, однако их ширина может самопроизвольно меняться. Часто находят спонтанный нистагам с наличием быстрых фаз, или же он легко вызывается при калорических пробах. Двигательных нарушений нет, или они носят преходящий характер в виде пластичного увеличения мышечного тонуса и патологических стопных знаков. В последуюшем характерна мышечная гипотония.

Таким образом, прогноз заболевания зависит от частоты и выраженности периодов декомпенсации посттравматического состояния. Как показал анализ литературных данных, посттравматические изменения представляют совокупность компенсаторно-приспособительных и сформировавшихся патологических процессов, которые могут самостоятельно развиваться и определять состояние больных. При этом патологические процессы, развивающиеся после травмы, имеют затяжное, прогрессирующее течение, трансформируются в различные неврологические симптомы и синдромы, приводят к инвалидизации и ранней смерти. Своевременное выявление и лечение этих патологических процессов с оценкой адаптационно-компенсаторных возможностей центральной нервной системы остается актуальной проблемой для клинической неврологии и требует дальнейшего изучения с использованием современных методов исследования. 


\section{ЛИТЕРАТУРА}

1. Агаева К. Ф. Процесс накопления и распространения последствий травмы головы среди населения. Журн. неврол. и психиатр. 2003 Т. 101. № 5. С. 46-48.

2. Аминов М. Компьютерная томография при последствиях ушибов головного мозга. Вести рентгенологии и радиологии. 1999. №6. С. 5-7.

3. Арбатская Ю. Д. Черепно-мозговая травма. Руководство по врачебно-трудовой экспертизе. М. 1989. T. 2. C. $395-430$.

4. Коновалов А. Н., Лихтерман Л. Б., Потапов А. А. Классификация черепно-мозговой травмы: сб. научных трудов ИНХ. М., 1997. С. 28-29.

5. Клиническая психиатрия / гл. ред. Т. Б. Дмитриева. М.: Медицина, 1990. С.161-178.

6. Лебедев В. В., Быковников Л. Д. Руководство по неотложной нейрохирургии. М.: Медицина, 1997. $336 \mathrm{c}$.

7. Лихтерман Л. Б., Потапов А. А., Кравчук А. Д. Современные подходы к диагностике и лечению черепно-мозговой травмы и ее последствий. Вопросы нейрохирургии. 1999. С. 245-292.

8. Раимкулов Б. Н. Разработка и внедрение альтернативных методов комплексной терапии легких черепно-мозговых травм: автореферат дисс... докт. Алматы, 2009. 36 с.

9. Рахова Р. К., Яковлев Н. А. Клинико-психовегетативные и метаболические нарушения у больных с последствиями легкой черепно-мозговой травмы. Нейроиммунология. 2003. Т.1, №2. С.124-125.
10. Штульман Д. Р. Неврология: справочник практического врача. Москва: Мед-пресс-информ, 2004. $820 \mathrm{c}$.

11. Bigler E. D. Brain imaging and behavioral outcome in traumatic brain injury. J. Learning Disabilities. 1996. V. 29, № 5. P. $515-530$.

12. Boake C., High W. M. Functional outcome from traumatic brain injury: unidimensional or multidimensional?. American J. Physical Medicine and Rehabilitation. 1996. V. 75, № 2. P. 105.

13. Evans B. M., Barlett J. R. Prediction of outcome in severe head injury based on recognition fsleep related activity in the polygraphic electroencephalogram. J. Neurol. Neurosurg. Psych. 1995. V. 59. P. $17-25$.

14. Factor S. A., J. Sanches-Ramos, J.W. Weiner et al. Trauma as an etiology of parkinsonism: opinions in the nineteenth century. Mov. Disord. 1989. Vol. 4, N 2. P. 283-285.

15. Mandel S., Sataloff R. T., Schapiro S. R. Minor head trauma. Springer - Verlag. 1993. № 8. P. 44.

16. Masters S. J., McClean P. M., Arcanese M. S., et al. Scull X-ray examinations after head injury: Recommendations by a multidisciplinary panel and validation study. N Engl J Med. 1987. 316. P. 84-91.

17. Rowland L. P. Merritt's textbook of neurology. 9th ed. Williams and Wilkins, 1995. P. 418-423.

18. Rudel V., Leitgeb J., Janciak I. et al. Тяжелая черепно-мозговая травма в Австрии. Вестник интенсивной терапии. 2008. №1. С. 41-46.

\section{REFERENCES}

1. Agayeva K. F. (2003). Prosess nakopleniya i rasprostraneniya posledstviy travmi golovi sredi naseleniya [The process of accumulation and spread of the consequences of head trauma among the population]. J. neurology and psychiatry, 5, 46-48.

2. Aminov M. (1999). Kompyuternay tomografiya pri posledstviyah ushibov golovnogo mozga [Computer tomography with the consequences of brain contusions]. To conduct X-ray and radiology, 6, 5-7.

3. Arbatskaya Y. D. (1989). Cherepno-mozgovaya travma [Manual on medical and labor expertise]. T. 2. M., 395430.

4. Konovalov A. N., Lihterman L. B., Potapov A. A. (1997). Klassifikatsiya cherepno-mozgovoy travmi [Classification of craniocerebral injury]. M., 28-29.

5. Dmitiyeva T. B. (1999). Klinicheskaya psihiatriya [Clinical psychiatry]. M.: Medicine, 161-178.

6. Lebedev V. V. Bikovnikov L. D. (1989). Rukovodstvo po neotlognoy neyrohirurgii [A guide to urgent neurosurgery]. M.: Medicine, 336.

7. Likhterman L. B., Potapov A. A., Kravchuk A. D. (2013). Sovramenniye podhodi k diagnostike i lecheniyu cherepno-mozgovoy travmi [Modern approaches to the diagnosis and treatment of craniocerebral trauma and its consequences]. Questions of Neurosurgery, 245-29.

8. Raimkilov B. N. (2009). Razrabotka Ivnadreniye altarnativnih metodov kompleksnoy terapii legkih cherepno-mozgovyh travm [Development and introduction of alternative methods of complex therapy of light craniocerebral injuries]. Alma-aty, 1-36.

9. Rakhova R. K. Yakovlev N. A. (2003). Klinikopsihovegetetivniye I metabolicheskiye narusheniya u bolnih s posledsnviyami legkoy cherepno-mozgovoy travmi [Clinico-psychovegetative and metabolic disorders in patients with consequences of mild craniocerebral trauma]. Neyroimmunology, 1, 2. 124-125.

10. Shtulman D. R. (2004). Nevrologiya. Spravochnik prakticheskogo vracha [Neurology: reference book of a practical doctor]. Moskva: Med-press-inform, 820.

11. Bigler E. D. (1996). Brain imaging and behavioral outcome in traumatic brain injury. J. Learning Disabilities, 29, 5, 515 - 530.

12. Boake C., High W. M. (1996). Functional outcome from traumatic brain injury: unidimensional or multidimensional?. American J. Physical Medicine and Rehabilitation, 75, 2, 105.

13. Evans B. M., Barlett J. R. (1995). Prediction of outcome in severe head injury based on recognition fsleep related activity in the polygraphic electroencephalogram. J. Neurol. Neurosurg. Psych., 59, 17 - 25.

14. Factor S. A., Sanches-Ramos J.,Weiner J.W. et al. (1989). Trauma as an etiology of parkinsonism: opinions in the nineteenth century. Mov. Disord., 4, 2, 283-285.

15. Mandel S., Sataloff R.T., Schapiro S. R. (1993). Minor head trauma. Springer-Verlag, 8, 44.

16. Masters S. J., McClean P. M., Arcanese M. S., et al. (1987). Scull X-ray examinations after head injury: Recommendations by a multidisciplinary panel and validation study. N Engl J Med., 316, 84-91.

17. Rowland L. P. (2003). Merritt's textbook of neurology. 9th ed. Williams and Wilkins, 418-423.

18. Rudel V., Leitgeb J., Janciak I. et al. (2008). Severe craniocerebral injury in Austria. Bulletin of Intensive Care, 1, 41-46. 


\title{
Резюме
}

\section{ДЕЯКІ АСПЕКТИ ПАТОГЕНЕЗУ ЧЕРЕПНО-МОЗКОВОЇ ТРАВМИ (ОГЛЯД ЛІТЕРАТУРИ) \\ Н.С. Мірзаєва \\ Ургенчський філіал Ташкентської медичної академії, м. Ургенч, Республіка Узбекистан}

Наведено огляд літератури, визначено особливості легкої черепно-мозкової травми. Описано низку синдромів, що виникають внаслідок легкої черепно-мозкової травми. Порушення внаслідок перенесених черепно-мозкових травм, набувають затяжного, проградієнтного перебігу з тривалою втратою працездатності серед осіб наймолодшого працездатного віку. Сучасна неврологія стикнулася 3 тенденцією зростання частоти черепно-мозкових травм із 25\% до 80\% від загальної кількості неврологічних захворювань. Це пов'язано із сучасними процесами урбанізації, впровадженням сучасних технологій, дорожньо-транспортних подій (АТП), локальними збройними конфліктами тощо. В основному травматизму зазнають особи чоловічої статі віком 20-50 років, що визначає його соціальну значущість. Наслідки гострої черепно-мозкової травми можуть бути різними: від цілковитого одужання до розвитку в 30-96\% випадків різних несприятливих ускладнень. Ао наслідків черепномозкової травми належить неврологічна патологія, що виявляеться за 3-12 місяців і більше потому, а клінічні прояви можуть зберігатися та видозмінюватися у вигляді окремих залишкових явищ.

Ключевые слова: черепно-мозкова травма, струс головного мозку, післятравматична амнезія.

\section{Summary}

\author{
SOME ASPECTS OF PATHOGENESIS OF CRANIOCEREBRAL INJURY \\ (LITERATURE REVIEW)

\section{N.S. Mirzaieva} \\ Urgench branch of the Tashkent Medical Academy \\ Urgench Republic of Uzbekistan
}

The article provides an overview of literature on traumatic brain injuries and their consequences. Violations occurring after suffering head injuries, get prolonged, progressive course with long-term disability among most of the young and of working age. Modern neuroscience has faced rising trend traumatic brain injuries from $25 \%$ to $80 \%$ of the total share of neurological diseases. This is due to modern processes of urbanization, the introduction of modern technology, traffic accidents (RTA), localized armed conflict and other factors. Most injury prone males aged 20-50 years (71.7\%), which defines its social value. After the injuries to $50 \%$ of the victims are forced to change their profession or go on disability. From $30-90 \%$ of individuals undergoing traumatic brain injury as a concussion or brain injury of mild to moderate severity of illness suffer traumatic brain. Outcomes of acute traumatic brain injury may be different from full recovery before the onset of $30-96 \%$ of the victims of various adverse effects and complications.

The effects of traumatic brain injury is a neurological abnormality detectable after 3-12 months or more after the injury and clinical manifestations may persist and evolve as individual residual effects.

Keywords: craniocerebral trauma, brain concussion, post-traumatic amnesia.

Інформація про автора знаходиться в редакиії. Дата надходження до редакиії 18.09.2018 p. 